\title{
Clientes, cidadãos, pacientes: reflexões sobre as múltiplas lógicas de cuidado na atenção à saúde
}

\author{
Clients, citizens, patients: considerations about the \\ multiple logics of care in health services
}

\author{
Mary Jane P. Spink' \\ Pontifícia Universidade Católica de São Paulo. Faculdade de \\ Ciências Humanas e da Saúde. Programa de Estudos Pós- \\ Graduados em Psicologia Social. São Paulo, SP, Brasil. \\ E-mail: mjspinkळpucsp.br
}

\section{Resumo}

Este ensaio tem por objetivo contribuir para a discussão sobre o cuidado na atenção à saúde, trazendo aportes da psicologia social discursiva em diálogo com a teoria ator-rede. Com base nas considerações da filósofa Annemarie Mol, propomos que diversas lógicas sobre o cuidado estão presentes nas interações entre profissionais e pessoas que com eles e elas interagem. Mol contrasta duas maneiras de lidar com a doença: a lógica do cuidado e a da escolha. E, mais especificamente, duas modalidades de escolha: a vertente do mercado, na qual pacientes são situados como clientes; e a vertente da cidadania, na qual os pacientes são considerados cidadãos portadores de direitos. Sendo a prática em saúde uma rede heterogênea de atores, essas distintas lógicas são acionadas em diferentes momentos, posicionando profissionais e usuários ora como pacientes, ora como cidadãos, ora como consumidores de produtos e serviços. Concluímos com a provocação de que temos de aprender a conviver com a polissemia de repertórios que circulam nos espaços que habitamos cotidianamente e com a fluidez dos jogos de posicionamento: reconhecer a partir de que posições nossos interlocutores falam e em que posições somos colocados.

Palavras-chave: Assistência à Saúde; Relações Interpessoais; Pessoalidade; Humanismo.

\section{Correspondência}

Rua Monte Alegre, 984. Perdizes.

São Paulo, SP, Brasil. CEP 05014-901.

1 A autora conta com o apoio do CNPq (bolsa produtividade). 


\section{Abstract}

The aim of this essay is to contribute to the discussion about care in health services, bringing to fore theoretical positions derived from discursive psychology in dialogue with actor-network theory. Based on the contributions of the philosopher Annemarie Mol, we propose that a diversity of logics of care is present in the interactions between professionals and people that seek health care. Mol makes a contrast between two ways of dealing with disease: the logic of care and the logic of choice, and, more specifically, two modalities of choice: the market version, where patients are considered as clients, and the civic version where patients are citizens that have rights. As heath practice is a heterogeneous network of actors, these different logics are mobilized at different moments positioning professionals and users sometimes as patients, as citizens and yet at other times as consumers of products and services. We conclude the essay with the provocation that we must learn to live with the polysemy of repertoires that circulate in the spaces we inhabit in our everyday lives and with the fluidity of positioning games: recognize from what person positions our interlocutors speak and in what positions we are placed.

Keywords: Delivery of Health Care; Interpersonal Relations; Personhood; Humanism.

\section{Introdução}

A noção de cuidado tem sido amplamente trabalhada na saúde coletiva, movida pelo debate sobre integralidade e humanização na atenção à saúde. Vide os textos instigantes de José Ricardo Ayres (2004); as coletâneas produzidas pelo Grupo Integralidades, que incluem um volume específico sobre o cuidar (Pinheiro; Mattos, 2007; Pinheiros; Silva, 2010); a proposta de Emerson Merhy a respeito de tecnologias leves e duras (Merhy, 200o); e as reflexões de Marilene Castilho de Sá acerca da intersubjetividade (2009). Embora pautadas em referenciais teóricos distintos, todas essas reflexões exaltam as características intersubjetivas do cuidado no contexto da atenção à saúde. Por exemplo, Sá afirma:

É possível concluir que a especificidade do trabalho em saúde, ou o que constitui sua essência, é sua característica intersubjetiva e de intervenção única de um sujeito sobre outro, em suas experiências singulares de vida, prazer, dor, sofrimento e morte. O caráter mais ou menos técnico-científico deste trabalho, seu grau de especialização, sua forma/ lógica de organização e de divisão técnica e social, suas finalidades, bem como as representações e valores a ele associados é que irão, obviamente, variar nos diferentes contextos histórico-sociais, alargando ou estreitando as margens da solidariedade e do cuidado com a vida (Sá, 2009, p. 656).

E Ayres, em texto já clássico, publicado em 2004 (p. 29), explica:

Quase sempre que se fala de Cuidado, humanização ou integralidade se faz referência a um conjunto de princípios e estratégias que norteiam, ou devem nortear, a relação entre um sujeito, o paciente, e o profissional de saúde que lhe atende. [...]

Com efeito, desde a aurora da Modernidade emergiu, junto a uma consciência histórica da existência humana, a consciência de que o adoecer é também histórica e socialmente configurado; de que tanto os determinantes do adoecimento quanto os saberes e instrumentos tecnicamente dirigidos a seu controle são fruto do modo socialmente organizado de homens e mulheres relacionarem-se entre si e com seu meio. 
A contribuição que trazemos, porém, introduz algumas peculiaridades que são próprias das vertentes críticas da psicologia social; ou, mais especificamente, de uma postura peculiar que mescla psicologia discursiva e abordagens vinculadas à teoria ator-rede. Da psicologia discursiva assentada em perspectivas construcionistas importamos, para a discussão sobre cuidado, a noção de pessoalidade que, conforme vem sendo por nós teorizada (Spink; Medrado, 1999; Spink, 2011), é intrinsecamente relacional. Da teoria ator-rede (TAR), importamos o princípio da simetria generalizada, segundo o qual o conhecimento e o significado não são uma propriedade exclusiva dos seres humanos; são efeitos ou produtos de redes heterogêneas de materialidades e socialidades (Law; Hassard, 1999; Latour, 2008). Porém, nos reportamos mais explicitamente às reflexões de John Law e Annemarie Mol (Law; Mol, 2002; Mol, 2002; 2008), que introduzem uma inflexão específica na TAR, enfatizando mais a performatividade do que a estabilização de objetos em redes.

Não se trata mais de acompanhar como os objetos se estabilizam em redes, mas sim, de lidar com um processo mais precário, contínuo, fluido, aberto, um modo nunca acabado de fazer existirem realidades.

(Moraes; Arendt, 2013, p. 315).

Nessa reconfiguração, o aspecto relacional extrapola as interações face a face, tornando-se mais fluido e circunstancial, dependendo do contexto em que o cuidado é performado. São relações plurais em contextos históricos e culturais também plurais.

Relações, possibilidades, pessoalidades tratadas assim, no plural, alertam para pressupostos ontológicos. Mais precisamente, situam as realidades, incluindo aquelas que são performadas, como múltiplas nos contextos das práticas de saúde. Começamos, pois, fazendo alguns apontamentos sobre o que vem a ser multiplicidade para a filósofa Annemarie Mol (1999).

\section{Sobre ontologias e suas implicações políticas}

Que postura é essa? Nas várias vertentes da teoria ator-rede, a questão ontológica é reconfigurada ao frisar que a realidade na qual vivemos é performada em uma variedade de práticas. A consequência radical disso é que a realidade é múltipla. Mas multiplicidade não implica laissez-faire. Sendo produto de práticas sociais, diferentes maneiras de performar a realidade têm consequências, têm efeitos que, também eles, extrapolam a situação imediata da ação. Maneiras de performar, portanto, têm conotações políticas.

Para analisar tais implicações, Mol (1999) utiliza a expressão ontological politics, esclarecendo que se trata de uma junção de dois termos: ontologia e política. Ontologia, na linguagem filosófica, tem a ver com as condições de possibilidade com as quais vivemos. Quando combinada com o termo "política, isto sugere que as condições de possibilidade não são dadas" (1999, p. 75); não antecedem as práticas mundanas; ao contrário, são por elas definidas. Em suma, o termo composto visa sublinhar a forma como o real está implicado na política e vice-versa. Nas palavras de Annemarie Mol, "a realidade não precede as práticas do mundo no qual nós interagimos, mas ela é re-moldada por essas práticas. Assim, o termo política permite referir-se a este tipo ativo de processo de moldagem e o fato de seu caráter ser tanto aberto como contestado" (1999, p 75, tradução nossa). Em suma, aceitar que há uma multiplicidade de maneiras de performar objetos coexistindo no presente suscita questionamentos que estão associados a escolhas que têm conotações políticas, entre eles: que opções existem?; o que está nelas implicado?; como escolher?; quem deve fazer as escolhas?

Mol argumenta que a realidade é histórica, cultural e materialmente localizada. Localizada onde? Por exemplo, nos estudos sociais da ciência, o laboratório foi reescrito como uma prática sociomaterial que faz existirem novas formas de se produzir realidades: telefones, vacinas, ratos geneticamente manipulados, motores de combustão, microchips, etc. Se a realidade é histórica e materialmente localizada, então ela é múltipla. E essa multiplicidade performática a diferencia de outras posturas que se pautam pela pluralidade, a exemplo do perspectivismo e do construcionismo.

Contra a singularidade da verdade única postulada pela voz anônima do especialista objetivo, as posturas perspectivistas propõem a existência de muitos especialistas com diferentes backgrounds profissionais e sociais ou até mesmo sem nenhum background-como no caso dos especialistas leigos - que trazem para suas interpretações habilidades específicas, hábitos, histó- 
rias, preocupações. Isso significa que seus olhos são diferentes, pois eles olham o mundo a partir de pontos de vista distintos. Assim, o perspectivismo rompeu com o monopólio da verdade única, porém não multiplicou a realidade: apenas multiplicou os olhos dos observadores. Tornou cada par de olhos que olha a partir de suas perspectivas uma alternativa para outros olhares, trazendo em seu rastro o pluralismo. Trata-se de alternativas mutuamente excludentes, discretas, existindo lado a lado num espaço transparente, enquanto o objeto que é foco desses muitos olhares permanece singular, intangível, intocado.

As posturas construcionistas também são formas de pluralismo. Esses contos construídos mostram como uma versão específica de realidade veio a existir, o que a sustenta, e como as alternativas a ela foram desacreditadas. São narrativas sobre os apoios utilizados para que fatos se tornassem reais: sustentos sociais - como atores e grupos envolvidos nessa construção -, bem como sustentos materiais: as lentes que serviram para objetivar a teoria das ondas de luz, ou a sala de dissecação com suas facas e destrezas que ancoram o fato de que a doença estabelece mudanças estruturais no corpo. Desse modo, os contos construtivistas sugerem que as alternativas de construção da realidade poderiam ter sido possíveis, mas não se concretizaram. Portanto, também aqui há pluralidade, só que, nesse caso, projetada ao passado: narrativas que poderiam ter sido, contudo não o foram - os perdedores perderam.

Falar sobre a realidade como algo múltiplo depende de outra série de metáforas. Não só sobre perspectivas e construção, mas também sobre intervenção e performance. Multiplicidade sugere que uma realidade é feita e objetivada e não meramente observada. Ao invés de uma diversidade de olhares incidentes sobre ela enquanto ela permanece intacta, a realidade é manipulada por meio de várias ferramentas no curso de uma diversidade de práticas.

Como tal, ao trabalhar com ontologias e suas implicações políticas, o que interessa é entender as práticas localizadas. 0 foco passa a ser a relação que se estabelece entre pessoas em contextos singulares. Então, nosso objetivo neste texto é problematizar a noção de cuidado em uma perspectiva relacional, pautada nas múltiplas versões que são ativadas em encontros relacionais. É nesse sentido ampliado que falaremos sobre práticas de cuidado e, por isso mesmo, colocaremos o termo "relação" entre aspas. Queremos falar de "relação" como as múltiplas possibilidades de se posicionar e ser posicionado, como fruto de nossas andanças pelo mundo: dentro e fora dos serviços de saúde; como profissionais de saúde e como usuários; como pessoas que negociam sentidos, afetações do corpo, ofertas de pílulas mágicas para recuperar o bem-estar, tecnologias de saúde.

\section{Sobre algumas versões de cuidado que circulam no contexto da atenção à saúde}

“Relação", na atenção à saúde, é um contexto de práticas histórico-culturais que são materialmente localizadas. Em sua conotação mais simples, envolve uma conversação entre um ou uma profissional e um ou uma paciente. Mas não é tão simples assim. Cada uma dessas pessoas está inserida em uma rede complexa de materialidades e socialidades. Por detrás da mesa que separa a médica e a paciente, há uma diversidade de outras pessoas e artefatos. No caso da médica, se fazem presentes as vozes de outros profissionais da equipe, de gestores, de antigos professores, de livros, de sites da internet onde buscamos novos conteúdos sobre doenças e tratamentos, de laboratórios que farão e/ou analisarão material biológico, de máquinas e mais máquinas. A capacidade de resposta dessa profissional depende de suas experiências passadas, de sua formação, de regulações e protocolos, de incentivos ou da falta deles, de apoio profissional e pessoal e das materialidades que embasam sua prática.

Também a paciente não está só: amigos, familiares que acompanham seu estado de saúde ou sua doença, as vicissitudes do transporte que a levará para casa, a possibilidade de acesso a exames e tantas outras "vozes" humanas e não humanas (sim, as máquinas "falam", mesmo que por meio de seus porta-vozes!). Porém essa "relação" depende ainda de como são posicionados os pacientes.

No livro The logic of care, publicado em 2008, Annemarie Mol contrasta duas maneiras de lidar com a doença: a lógica do cuidado e a lógica da escolha (logic of choice). Segundo ela, a lógica da escolha adentrou os serviços de saúde trazendo consigo (ou sendo trazida por) formulários de consen- 
timento informado, litígios, presença de anúncios sobre medicamentos e tratamentos, e as múltiplas informações sobre estilos de vida que, obviamente, dependem da adesão - por escolha - dos pacientes (mesmo que nunca tenhamos tempo para ler as letras pequenas dos consentimentos informados que assinamos quando fazemos certos exames ou nos submetemos a alguns procedimentos médicos). Para Mol, a lógica da escolha não combina muito com a doença e, assim, ela pergunta em que medida a lógica da escolha interfere no bom cuidado.

A autora adverte que lógica, no caso, não se refere a regras de raciocínio, como na filosofia, mas aos modos de ordenação, que se tornam mais compreensíveis quando comparados a outras lógicas, como a do cuidado. Para efetuar o contraste, Mol escolhe uma doença específica, o diabetes tipo 1, e realiza um estudo etnográfico em um hospital holandês.

\section{Sobre a lógica da escolha}

Como há muitas versões de escolha, assim como há muitas versões de cuidado, Mol focaliza duas modalidades da lógica da escolha: a vertente do mercado, em que pacientes são situados como clientes e a vertente da cidadania, na qual os pacientes são considerados cidadãos portadores de direitos.

Comecemos pela lógica da escolha na qual a linguagem prevalente é a do mercado. Na linguagem do mercado, as pessoas têm direito a obter aquilo pelo qual pagaram - direitos de consumidores -, e a oferta de serviços de saúde, nesse aspecto, deveria seguir a demanda, como no caso dos planos de saúde. Mol faz, então, uma primeira distinção entre cuidado e escolha. Nas palavras dela: "O cuidado não é uma transação na qual algo é trocado (um produto por um preço); é uma interação na qual a ação vai e vem (em um processo contínuo)" (Mol, 2008, p. 21, tradução nossa). O que conta, na lógica do cuidado, é o resultado, e como as tarefas serão divididas entre os vários atores segue daí. É um processo aberto, em contraste com a lógica do mercado que se pauta pela transferência do produto: tem um começo e um fim.

Na lógica da escolha, na versão do mercado, as pessoas são denominadas "clientes" em vez de pacientes, pois, etimologicamente, o termo paciente remete à passividade. Na lógica do cuidado, as pes- soas que buscam ajuda são denominadas pacientes por boas razões: elas sofrem. Porém isso não implica passividade, ainda que as atividades de cuidado incluam médicos, enfermeiras, máquinas, agulhas, drogas, etc., os pacientes também têm de fazer muitas coisas. Assim, no caso de portadores de diabetes 1, é preciso comer antes de entrar em hipoglicemia, injetar insulina, medir a glicose, fazer exercícios. Não há nada de passivo nesses pacientes.

Uma outra vertente da lógica da escolha é a da cidadania. Nas políticas de Estado, somos posicionados como cidadãos, e as relações entre as pessoas são referidas como “contratos". É nesse contexto que emergem leis que regulam as relações entre profissionais e pacientes-cidadãos. "Os profissionais devem suprir seus pacientes com informações e depois perguntar o que querem. Só podem agir quando seus pacientes derem seu consentimento explícito e, se houver distintas opções, os pacientes deverão ter o direito legal de escolher entre elas" (Mol, 2008, p. 34, tradução nossa).

Quando procuramos entender cuidado com base na lógica da cidadania, observamos que vários modelos foram formatados historicamente. Na Grécia, o modelo do controle do corpo, na vertente do mens sana corpore sano; no processo civilizatório associado ao ideal burguês, o controle das paixões e o império dos bons modos; no iluminismo, a transcendência do corpo na busca da liberdade. Mas em nenhum desses casos, o foco era o corpo doente.

O que essas diversas variantes de cidadania têm em comum é que os corpos desses cidadãos nunca interferem com seus planos. "Por definição", um cidadão é alguém que controla seu corpo, que o domestica, ou dele escapa. "Cidadãos" possuem a habilidade de fazer suas próprias escolhas no silêncio de seus corpos. (Mol, 2008, p.35, tradução nossa)

Ou seja, na lógica da escolha, na vertente da cidadania, é necessário que esses corpos sejam subjugados, domesticados. Então, como levar os pacientes a sério? Para Mol, não se trata de estabelecer uma equivalência entre pacientes e pessoas sãs, mas de estabelecer como padrão "viver com a doença" ao invés da "normalidade". É um convite a subverter categorias instituídas que colocam ser saudável como padrão hegemônico. Assim, tal como fizeram as femi- 
nistas questionando a dicotomia homem-mulher, Mol propõe que adotemos o "pacientismo" como maneira de reconfigurar a posição de pacientes na sociedade.

\section{Contrastando lógicas de cuidado}

Em qualquer dessas duas versões - a do mercado ou a da cidadania -, na lógica da escolha, a informação científica é concebida como uma coleção crescente de fatos que, gradativamente, aumentam a certeza na tomada de decisão. Nesse sentido, a função dos profissionais da saúde é fornecer informação aos pacientes. Com os fatos devidamente delineados, alguém tem que definir o valor de diversos cursos de ação. "Porém, considerando que tomar decisões é uma questão de equilibrar valores, não há nenhuma razão pela qual médicos ou enfermeiras devam fazer isso. Uma vez que o tratamento interfere com a vida dos pacientes, são os valores dos pacientes que deveriam contar mais" (Mol, 2008, p. 48, tradução nossa).

Isto é, a lógica da escolha separa fatos e valores; em contraste, a lógica do cuidado trata-os conjuntamente. Assim, na lógica do cuidado, coletar informações não é um modo de ter melhores mapas da realidade, mas de artesanalmente criar maneiras mais toleráveis de viver com ou na realidade. Mol ilustra esse ajustamento contínuo com o caso do Sr. Zomer, um operário de construção, que havia sido diagnosticado com diabetes tipo 1 e instruído a medir a glicose cinco vezes por dia para obter um bom baseline. Embora parecesse estar bastante motivado, ele retornou ao serviço de saúde sem ter feito as mensurações, pois, trabalhando na rua, não havia como fazê-las. Criou-se, então, espaço para que ele pudesse falar sobre sua frustação. No contexto da lógica do cuidado, trabalha-se com praticidades: como conciliar as dificuldades de mensuração na situação de trabalho? Talvez fosse possível medir uma vez por dia em cinco dias seguidos ao invés de cinco vezes ao dia.

Na lógica do cuidado, como na contabilidade, busca-se o balanço entre crédito e débito. Mas o balanço não se reduz à soma e à subtração de vantagens e desvantagens, pois não há variáveis fixas. Esse equilíbrio tem que ser estabelecido ativamente, ajustando variáveis viscosas. Mol chama de viscosidade os hábitos, pessoas, condições materiais que não se submetem às nossas vontades.
Mais um contraste: na lógica da escolha, o pressuposto é que a opção seja confinada a um momento específico. Já a lógica do cuidado sugere que o ajuste das muitas variáveis viscosas da vida seja um processo contínuo. Então, na lógica da escolha, o tempo é linear e o momento chave é a escolha decorrente da sequência que leva dos fatos (que são supostamente neutros) à escolha (que é prenhe de valores) e daí à ação (que é meramente técnica). Em contraste, o tempo da lógica do cuidado é fluido, cheio de idas e vindas.

Na lógica da escolha, as pessoas são consideradas iguais; na lógica do cuidado, não: as pessoas têm necessidades distintas de modo que adição e divisão não estão em pauta, mas sim, diferenciação e especificidade. Dessa forma, tentar melhorar a saúde pública por meio de persuasão para que os indivíduos escolham uma vida saudável, como na saúde promocional, não é uma boa ideia, pois as campanhas de saúde pública são genéricas, já que não fazem diferenciações entre pessoas específicas e situações específicas - tratam todos como iguais.

Portanto, na perspectiva da saúde coletiva, o bom cuidado implicaria mexer nas condições nas quais esses coletivos vivem.

Ao invés de dizer o que os indivíduos deveriam escolher, essas intervenções de cuidado deveriam melhorar as condições coletivas sob as quais vivemos. Ao invés de nos obrigar a exercitar nossas forças de vontade, elas deveriam nos ajudar a cuidar de nossos corpos. (Mol, 2008, p. 8o, tradução nossa).

Quanto à moralidade, ambas as lógicas têm sua normatividade: enquanto na lógica da escolha autonomia e igualdade são boas e opressão é ruim, na lógica do cuidado, atenção e especificidade são boas e negligência é má; não há equivalência entre uma e outra. A normatividade na lógica da escolha vem em camadas. Na primeira camada, a possibilidade de escolha é boa, pois permite exercitar autonomia; e igualdade é boa, porque todos os indivíduos devem ter a oportunidade de escolha. Na segunda camada, na lógica da escolha, são feitos julgamentos, mas para cada uma das duas modalidades discutidas por Mol (clientes e cidadãos) há diferentes estilos de julgamento. $\mathrm{Na}$ modalidade de mercado, avalições são feitas individualmente; é uma questão privada. Na modalidade da cidadania, questões éticas são discutidas em público. 
Busca-se, a partir do debate público, contrastar argumentos a favor ou contra e chegar a um veredito.

Porém, na lógica do cuidado, o ato moral por excelência não é fazer julgamentos, mas engajarse em atividades práticas. Só há uma camada. O importante é fazer o bem, melhorar a vida, porém este "bem" não é dado a priori, mas envolve coletivos; mais precisamente, envolve práticas situadas (local doctoring). Na lógica do cuidado, o que é bom ou mau nunca é fixo. "As boas conversas no consultório não assumem o formato de confronto de argumentos; são marcadas pela troca de experiências, conhecimentos, sugestões, palavras de conforto" (Mol, 2008, p. 87). Assim, a tarefa de cuidar nunca é fácil, e a boa comunicação é uma condição essencial do bom cuidado.

Então, do que depende um bom cuidado:

1. Como o cuidado é essencialmente associado a práticas que colocam face a face pacientes e um ou mais profissionais de saúde, depende, antes de tudo, das condições dessa prática; certamente as habilidades profissionais são fundamentais, mas também são relevantes as características organizacionais dos serviços onde ocorrem esses encontros.

2. Desde os anos 196o, foram feitos muitos estudos sobre esses encontros nos serviços de saúde e, de modo geral, eles têm sido críticos. Mas não basta a crítica, iniciada com os estudos da sociologia e antropologia da doença, é preciso reverter a tendência iluminista da racionalidade e transpor para a clínica o mundo vivido.

3. É preciso, portanto, que a realidade vivida pelos pacientes seja incorporada nas pesquisas científicas, para além das interpretações que pesquisadores bem-intencionados fazem dessas vivências. Isso exige novos métodos, entre eles, a incorporação de narrativas pessoais nos trabalhos sobre atenção à saúde, não só por meio dos estudos de caso tradicionais, mas aquelas supridas e enriquecidas por todos: membros da equipe, pacientes e outras pessoas envolvidas nesses eventos. Por conseguinte, narrativas multivocais. E essas narrativas têm que circular em outros espaços, que permitam experimentação, e não ficarem confinadas nos circuitos acadêmicos e profissionais.

\section{Considerações finais}

Conforme apontamos na introdução, as características intersubjetivas do cuidado no contexto da atenção à saúde vêm sendo enfatizadas por muitos autores no que diz respeito à saúde coletiva. Porém, há dois aspectos especificamente associados à mescla que vimos fazendo entre a abordagem das práticas discursivas na vertente construcionista e os aportes da TAR, os quais merecem destaque.

Em primeiro lugar, a relação aqui discutida envolve considerável contingente de atores. São vozes que estão presentes nos encontros entre profissionais e pacientes. Contudo, não são apenas vozes humanas. Ou se humanas, são também porta-vozes de atores não humanos. Como agilizar uma "boa relação" sem acesso a certas materialidades como papel e caneta, formulários, estetoscópio? E como performar cuidado sem tornar actantes aqueles que não estão imediatamente presentes, como laboratórios, agulhas de injeção, frascos para armazenar sangue; microscópios, etc? Portanto, o que queremos pontuar é que relações se dão em redes heterogêneas que são ativadas nos encontros. Sem levar em consideração essas redes heterogêneas de actantes, boas intenções nas práticas de cuidado são, muitas vezes, frustradas.

Por exemplo, a dissertação de mestrado de Samanta Cunha (2013) foi realizada em um Ambulatório de Saúde da Mulher em Jundiaí, SP, que é Centro de Referência de oncologia para oito municípios da região. Foram feitas observações e registro de eventos e conversas entre profissionais e destes com pacientes, assim como entrevistas com mulheres que passavam por diferentes fases de diagnóstico e tratamento. A análise dessas informações possibilita concluir que, para além da interação com as profissionais do serviço, a experiência dessas mulheres é pautada também pelas atribulações do percurso terapêutico, assim como pelos sentimentos e preconceitos que cercam o câncer.

Por meio da fala de quatro mulheres entrevistadas, pudemos perceber que a convivência com o câncer é permeada por tabus, medos e sombras que ainda mistificam a doença, resquícios do seu curso no tempo longo da história. No entanto, esse não é o único desafio que as mulheres encontram no seu percurso terapêutico. 0 sofrimento vem também 
da maneira desrespeitosa com que são tratadas por alguns profissionais de saúde; do penoso caminho burocrático para conseguir o laudo médico junto ao INSS e, assim, receber o benefício a que têm direito; do estigma que a doença acarreta e, consequentemente, do afastamento das pessoas que amam. (Cunha, 2013, p. 115).

Todavia, há também outro aspecto: pacientes e profissionais não são entidades fixas. Não são cristalizados em identidades facilmente decifráveis. Há muitas posições de pessoas ofertadas e/ou assumidas por profissionais e por pacientes. Seguindo Annemarie Mol, pessoas que procuram serviços de saúde (ou são por eles convocados) respondem a muitas lógicas. Ora são consumidores que têm direitos, não apenas porque compram serviços, como nos planos de saúde privados, mas também porque são mobilizados pelos apelos de fármacos e de promessas de vida saudável pelo uso de equipamentos ou de medicamentos. O mercado adentra as portas dos serviços diretamente por meio de revistas para leitura, da TV ligada eternamente para distrair os usuários enquanto aguardam serem atendidos em ambulatórios ou terem alta no caso das internações e pronto-atendimentos, além das conversas nas salas de espera. E também indiretamente, por meio dos repertórios que aprendemos a usar por circularmos pelo mundo. Ora são cidadãos, que têm direitos assegurados em legislações - e mesmo que não os conheçam, certamente estão cercados por outros que os conhecem: profissionais, conselheiros de saúde e advogados que rondam à procura de causas a defender. Também são pacientes, no sentido mais chulo de pessoas que pacientemente aguardam a boa vontade dos profissionais e as orientações que deverão seguir, como boas ovelhas. No entanto, até mesmo estes pacientes são polissêmicos. Somos pacientes diante de nossas doenças, de nossos mal-estares. E é a esses pacientes que as provocações de Mol se voltam, na insistência de que pacientes não são nada passivos. $\mathrm{Na}$ lógica do cuidado, esses pacientes fazem muitas coisas. No exemplo do diabetes 1, injetam insulina, prestam atenção a seus corpos, calculando o que comem, medindo a glicemia, ficando antenados aos sintomas e sensações corporais. Ser ativo, obviamente, não implica estar sozinho; na lógica do cuidado, a ação circula entre muitos atores, mas é sempre algo prático, que envolve pequenas ações cotidianas.
Retomamos, portanto, como temos feito em tantos outros textos (Spink, 2007), à provocação de que temos de aprender a conviver com a polissemia de repertórios que circulam nos espaços que habitamos cotidianamente e com a fluidez dos jogos de posicionamento: reconhecer a partir de que posições nossos interlocutores falam e em que posições somos colocados.

Não é uma tarefa fácil. Recentemente, estivemos na posição de acompanhante de paciente em um renomado hospital de São Paulo; uma instituição que situa "cuidado com o calor humano" como um dos três pilares de sua missão (sendo os demais o conhecimento e a filantropia). o Manual de Orientação ao Paciente que recebemos no momento da internação é um belo exemplo de postura que valoriza o acolhimento do paciente. Ele nos traz informações sobre o hospital, os serviços que oferece, os procedimentos relacionados à internação, e ainda os direitos e deveres dos pacientes. 0 termo utilizado é sempre "paciente", com exceção justamente do breve texto introdutório:

Prezado(a) paciente. Seja bem-vindo(a) ao Hospital $x x x$. Proporcionar aos nossos clientes um atendimento ágil e humanizado é prioridade para a equipe de profissionais do $x \times x$. (grifo nosso)

Mas a lógica do mercado também se faz presente, sobretudo na solicitação reiterada de avaliação por parte dos pacientes:

A manifestação do paciente sobre os serviços e o atendimento prestado durante sua permanência é muito importante para o Hospital XXX, que com esses dados pode aperfeiçoar-se cada vez mais.

Essas avaliações podem ser feitas por vários meios: formulários disponibilizados nos vários andares do hospital, por telefone do SAC, e-mail, carta ou fax. Todos, porém, serão analisados pelo Serviço de Atendimento ao Cliente (SAC). Afinal, um hospital é uma empresa e manter a acreditação de institutos internacionais da área da saúde é fundamental para o sucesso desse empreendimento.

Também a lógica da cidadania se evidencia. A seção voltada a direitos e deveres, por exemplo, tem como base cinco referências legais: Direitos dos usuários dos Serviços e das Ações de Saúde do Estado de São Paulo (Lei Estadual 10.241/1999); Código Civil 
Brasileiro; Código de Defesa do Consumidor; Estatuto do Idoso; e Estatuto da Criança e do Adolescente.

Em suma, como usuários de serviços de saúde, ocupamos potencialmente todas estas posições: pacientes, clientes, cidadãos. Nós, assim como os profissionais que cuidam de nós!

\section{Referências}

AYRES, J. R. C. M. O cuidado, os modos de ser (do) humano e as práticas de saúde. Saúde e Sociedade, São Paulo, v. 13, n. 3, p. 16-29, 2004.

CUNHA, S. M. Percursos, enfrentamentos e apoios na convivência com o câncer de mama. 2013. Dissertação (Mestrado em Psicologia Social)Pontifícia Universidade Católica de São Paulo, São Paulo, 2013.

LAW, J.; HASSARD, J. (Org.). Actor network theory and after. Oxford: Blackwell, 1999.

LAW, J.; MOL, A. (org.). Complexities: social studies of knowledge practices. Durham: Duke University Press, 2002.

LATOUR, B. Reensamblar lo social: una introducción a la teoría del actor-red. Buenos Aires: Manantial, 2008.

MERHY, E. Um ensaio sobre o médico e suas valises tecnológicas: contribuições para compreender as reestruturações produtivas do setor Saúde. Interface, Botucatu, v. 4 n. 6, p. 109-116, 2000.

MOL, A. Ontological politics: a word and some questions. In: LAW, J.; HASSARD, J. (Org.). Actor network theory and after. Oxford: Blackwell, 1999. p. 74-89.
MOL, A. The body multiple: ontology in medical practice. Durham: Duke University Press, 2002.

MOL, A. The logic of care: health and the problem of patient choice. Oxford: Routledge, 2008.

MORAES, M. O.; ARENDT, R. J. J. Contribuições das investigações de Annemarie Mol para a psicologia social. Psicologia em Estudo, Maringá, v. 18, n. 2, p. 313-321, 2013.

PINHEIRO, R.; MATTOS, R. A. Razões práticas para a integralidade em saúde: o cuidado como valor. Rio de Janeiro: IMS: ABRASCO, 2007.

PINHEIRO, R.; SILVA JR, A. G. Por uma sociedade cuidadora. Rio de Janeiro: CEPESC: ABRASCO, 2010.

SÁ, M. de C. A fraternidade em questão: um olhar psicossociológico sobre o cuidado e a "humanização" das práticas de saúde. Interface, Botucatu, v. 13, p. 651-64, 2009. Suplemento 1.

SPINK, M. J. P. Sobre a possibilidade de conciliação do ideal da integralidade nos cuidados à saúde e a cacofonia da demanda. Saúde e Sociedade, São Paulo, v. 16, n. 1, p. 18-27, 2007.

SPINK, M. J. P. Pessoa, indivíduo e sujeito: notas sobre efeitos discursivos de opções conceituais. In: SPINK, M. J. P.; FIGUEIREDO, P.; BRASILINO, J. (Org.). Psicologia social e pessoalidade. Rio de Janeiro: Biblioteca Virtual de Ciências Humanas do Centro Edelstein de Pesquisas Sociais, 2011. p. 1-22.

SPINK, M. J. P.; MEDRADO, B. Produção de sentidos no cotidiano: uma abordagem teórico-metodológica para análise das práticas discursivas. In: SPINK, M. J. P. (Org). Práticas discursivas e produção de sentidos no cotidiano: aproximações teórico e metodológicas. São Paulo: Cortez, 1999. p. 41-61.

\footnotetext{
Recebido: 30/01/2014

Reapresentado: 08/08/2014

Aprovado: 15/09/2014
} 